\title{
Reflexões acerca da Iatrogenia e Educação Médica
}

\author{
Reflections about Medical Education and \\ Iatrogenesis
}

Felipe de Medeiros Tavares ${ }^{1}$

PALAVRAS-CHAVE:

- Educação Médica;

- Iatrogenia;

- Medicina Psicossomática.

KEY-WORDS:

- Education, Medical;

- Iatrogenic Disease;

- Psychosomatic Medicine.

Recebido em: 06/06/2006

Reencaminhado em: 14/02/2007

Aprovado em: 13/04/2007

\section{ABSTRACT}

latrogenesis refers to a psychical or physical harm, caused by medical treatment. However, any professional may commit a medical error, and this depends not only on his technical capacity but also on the doctor-patient relationship. Medical education plays therefore a primordial role in the construction of future physicians less subject to commit Iatrogenesis. This paper approaches the topic from a conceptual view, aiming at encouraging further reflections and discussions in the medical community. 


\section{INTRODUÇÃO}

Iatrogenia é uma palavra que deriva do grego: o radical iatro ("iatrós"), significa médico, remédio, medicina; geno ("gennáo"), aquele que gera, produz; e "I $a$ ", uma qualidade.

A iatrogenia poderia, portanto, ser entendida como qualquer atitude do médico. Entretanto, o significado mais aceito é o de que iatrogenia consiste num resultado negativo da prática médica. Nesse sentido, um médico, ainda que disponha dos melhores recursos tecnológicos diagnósticos e terapêuticos, é passível de cometer iatrogenias. Michael Balint ${ }^{1}$ reformulou este conceito ao afirmar que todo médico é, em graus variáveis, iatrogênico, de modo que ele deve sempre considerar esse aspecto quando trata seu paciente. Outros autores enfatizam que o fato de os médicos lidarem com riscos os torna sujeitos a cometer iatrogenias ${ }^{2}$.

Nesse âmbito, a denominação mais adequada poderia ser "iatropatogenia", termo que enfatiza a noção maléfica do ato médico, isto é, um ato que provocará prejuízos ao paciente3. Iatrogenia (ou iatrogenose, iatrogênese) abrange, portanto, os danos materiais (uso de medicamentos, cirurgias desnecessárias, mutilações, etc.) e psicológicos (psicoiatrogenia - o comportamento, as atitudes, a palavra) causados ao paciente não só pelo médico como também por sua equipe (enfermeiros, psicólogos, assistentes sociais, fisioterapeutas, nutricionistas e demais profissionais) $)^{4}$.

Sob esta óptica, os "erros médicos", tais como os conhecemos no Código de Ética Médica (imperícia, imprudência, negligência) se enquadram na categoria de iatrogenias, no entendimento contemporâneo ${ }^{5}$.

Inúmeros são os trabalhos publicados na literatura acerca da iatrogenia entendida como falhas do médico relacionadas a procedimentos, efeitos colaterais de medicamentos prescritos, oriundas de procedimentos cirúrgicos, etc. (iatrogenia direta). Pretende-se aqui abordar o tema de maneira mais ampla, porque a iatrogenia envolve outros aspectos da prática médica, como, por exemplo, a iatrogenia indireta (exercida por meio do contato interpessoal), que possui elevado impacto social. A educação médica tem papel relevante na profilaxia de eventos iatrogênicos, ao fornecer instrumentos necessários a melhor compreensão do tema pelos graduandos.

Pretende-se, neste artigo, abordar de forma sucinta alguns princípios relacionados a esse tema, que é pouco trabalhado em nosso meio.

\section{SITUAÇÕES QUE FAVORECEM A OCORRÊNCIA DE IATROGENIAS}

São inúmeras as situações na prática clínica, e mesmo no ensino, que favorecem a ocorrência de iatrogenoses. De forma bastante sucinta, elas podem ser assim agrupadas:

\section{Quanto ao Modelo Biomédico}

A filosofia cartesiana, que inspirou a conduta médica ocidental, estabelece a dicotomia psique/soma que, corroborada por outra díade, doente/doença, contribui para o estabelecimento de uma visão fragmentada do paciente.

O médico perde, assim, a sensibilidade de enxergar esse paciente como um todo biopsicossocial (sujeito na sua integralidade), tratando apenas dos sintomas aparentes, como se o paciente fosse uma máquina que necessitasse de ajustes, um quebra-cabeça ${ }^{6}$.

A prática clínica ocidental está baseada apenas nas doenças, com a crescente desvalorização da escuta. Esse é um dos motivos pelos quais a sociedade vem exigindo o retorno do "médico de família" e mesmo o direito a serviços médicos não alopáticos. A superespecialização, acompanhando o progresso da tecnologia e o crescente fenômeno da medicalização da sociedade ${ }^{7}$, faz com que o paciente se sinta pressionado a visitar diversos profissionais para o acompanhamento de determinado transtorno. E o paciente torna-se cada vez mais carente. A quase exigência de uma receita médica ou pedido de exame cada vez que consulta um médico é uma prova disso. A questão da "eficiência e rapidez" no tratamento já está tão difundida entre os sujeitos que demandam o cuidado, que o profissional pouco se dedica às outras questões relevantes no estabelecimento da enfermidade em questão: os fatores sociais, ambientais, hereditários, psicológicos, culturais, religiosos e políticos ${ }^{6}$.

\section{No Âmbito da Relação Médico-Paciente}

Os aspectos psicodinâmicos da relação médico-paciente devem ser percebidos pelo médico a fim de que ele possa compreender que tais fenômenos interferem no cerne desta relação.

O futuro médico deve compreender que o paciente, pela condição em que se encontra, idealiza muito a figura do médico (como um demiurgo). O indivíduo que demanda cuidados traz ao encontro com o médico uma série de expectativas e fantasias quanto à figura deste e quanto ao desenvolvimento da consulta. Tais fatores, conforme veremos adiante, poderão contribuir para a ocorrência de iatrogenias.

Deve-se dar a importância devida aos fenômenos contidos em toda relação médico-paciente, os quais são estudados por alunos de Medicina mormente na disciplina de Psicologia Médica (transferência, contratransferência e mecanismos de defesa - negação, projeção, racionalização, repressão). Nesse sentido, determinados modelos de relação médico-paciente permitem que as iatrogenias aconteçam com mais facilidade. Um bom exemplo é o da medicina de urgência, onde por vezes o 
paciente está tão debilitado, que a relação é por si só assimétrica. Este paciente pouco participa da relação (paciente passivo, submisso), e o profissional assume uma posição de superioridade, sem consultar o paciente para qualquer procedimento. Quando o paciente "desperta" para a situação, mesmo sabendo que determinados procedimentos eram cruciais naquele momento, pois visavam sua sobrevivência, pode ser difícil admiti-la. É o caso dos pacientes vítimas de traumatismos que tiveram de ser submetidos a uma traqueotomia, por exemplo.

O paciente crônico, que percorre vários profissionais a fim de obter um diagnóstico "seguro" para a sua enfermidade ou uma "segunda opinião", costuma não estabelecer vínculos afetivos com o médico, o que pode contribuir para o estabelecimento de situações iatrogênicas.

O mesmo ocorre em ocasiões nas quais médico e paciente procuram não se envolver emocionalmente. Predomina a linguagem técnica, a frieza ${ }^{1}$. Outro exemplo de iatrogênese é a situação provocada pelo uso da anamnese dirigida, que camufla a hostilidade do médico, já nos dizia Perestrello ${ }^{8}$.

Situações nas quais, por outro lado, o envolvimento do médico com seu paciente se torna muito intenso, a ponto de enfraquecer os limites entre os egos de ambos, favorecem a geração de respostas emocionais no médico, como luta/submissão, indiferença ou ainda excesso de dedicação ao paciente. Pode-se dizer que existe aqui um desequilíbrio nos fenômenos de transferência/contratransferência, que se tornam patológicos. A relação passa então a ser assimétrica, com repercussões negativas na pessoa do paciente e na própria identidade médica. Este fenômeno é conhecido como indução iatrogênica ${ }^{9}$. Exemplificando, temos aquele paciente que insiste com o médico em realizar uma cirurgia absolutamente desnecessária e arriscada. Capisano ${ }^{10}$ salienta que conflitos neuróticos do médico podem se manifestar como iatrogenias, sendo eles a insegurança (manifestada pelo excesso de pedidos de exames complementares), o narcisismo (o paciente é tratado com desdém), o sadismo inconsciente (conforme ocorre com os pacientes submetidos a sucessivos exames invasivos) e, por fim, os conflitos inerentes às diferentes especialidades, como o pediatra, que pode induzir à hipocondria em virtude dos cuidados excessivos que prescreve ao paciente.

A sensibilidade diagnóstica, sobrepujada pelos excessivos pedidos de exames complementares, pode favorecer o estabelecimento de diagnóstico equivocado, com o conseqüente tratamento de uma enfermidade que o paciente não possui.

Finalmente, a linguagem não-verbal influencia sobremaneira a conduta terapêutica e é percebida pelo paciente: gestos, linguajar, trajes, disposição dos móveis, cor das paredes do consultório, etc.

\section{Outras Situações Causadoras de Iatrogenia}

Outros fatores concorrem com freqüência para a manifestação de iatrogenias. Por exemplo, as más condições de trabalho, queixa freqüente entre professores e médicos: o profissional trabalha mais tempo por dia, em diferentes locais, atendendo uma quantidade crescente de pacientes, em consultas rápidas. Além disso, as condições físicas do estabelecimento podem influenciar a conduta do profissional. O prontuário médico - que deveria ser o melhor "parceiro" do médico acaba sendo preenchido de maneira inadequada, incompleta, não sendo registradas ali informações relevantes acerca das características do paciente e do seu processo de adoecer. A inexatidão dos dados contidos no prontuário, bem como a maneira como este é preenchido (a caligrafia incompreensível, por exemplo) favorecem a iatrogênese. A interdisciplinaridade e a busca da prática da integralidade no ambiente de trabalho, quando estabelecidas, atenuam o número de situações iatrogênicas.

A justificativa já consagrada de que o médico é humano como qualquer outro profissional e, portanto, tem as mesmas possibilidades de cometer falhas, embora seja pertinente, ainda não recebe o devido respaldo social. Como dito anteriormente, o fato de o paciente idealizar o médico não permite que ele tolere falhas justamente daquele que "deve ser capaz de curar e salvar vidas".

\section{No Âmbito da Formação Médica}

Ao longo da formação acadêmica, a identidade do médico vai sendo constituída, de tal sorte que essa identidade pode se tornar iatrogênica desde o momento em que o aluno optou pelo curso médico, época de grandes expectativas. A decisão pelo curso ocorre num momento de vários conflitos (adolescência), e geralmente faltam esclarecimentos ao vestibulando acerca da história do curso médico, de seus meandros, enfim, de seus propósitos. A vocação médica pode, nesse momento, ser sobrepujada por outros interesses em jogo, como busca de reconhecimento e prestígio social, satisfação dos desejos dos pais, ganhos financeiros, etc. Pseudovocações podem culminar em identidades frágeis, hostis, erradias, portanto iatrogênicas.

A medicina é, sobretudo, humana e requer do futuro médico capacidades para lidar com frustrações, paciência, perseverança, dedicação. Nem todos os indivíduos aptos no processo seletivo (vestibular) possuem inclinação para o curso médico. A avaliação do vestibular é falha, porque se baseia estritamente em critérios mnemônicos. É comum observarmos indivíduos portadores dos mais diversos distúrbios psicológicos e psiquiátricos optarem pelo curso como uma for- 
ma de ocultar tais situações. Indivíduos instáveis emocionalmente estão mais dispostos a cometer iatrogenias ${ }^{2 ; 11}$.

Além disso, os professores possuem destacado papel na constituição de uma identidade iatrogênica ou saudável ${ }^{12}$. Os alunos identificam-se com a figura do mestre, e este deve estar atento a que suas atitudes, seus gestos, a maneira de lidar com os alunos e com os pacientes são aspectos introjetados pelos aprendizes e que poderão ser reproduzidos em suas relações com os sujeitos enfermos. A categoria da "didatopatogenia" ou "didatoiatrogênese" consiste justamente na construção de identidades iatrogênicas a partir das atitudes também iatrogênicas oriundas dos mestres. Por exemplo, os professores que discutem os casos clínicos na frente dos pacientes, gerando reações neuróticas nestes. Isso poderá prejudicar o aluno, especialmente aqueles que se encontram em plena "crise do terceiro ano" (reações emocionais provocadas pelo encontro com os pacientes pela primeira vez $)^{9}$.

$\mathrm{O}$ ensino na maioria das instituições médicas tende a valorizar a especialização precoce. Isso pode ser constatado pelo fato de os nossos professores serem, na maior parte, especialistas, lecionando para indivíduos que se graduarão como generalistas. Depois, quando se gradua, o médico tem de fazer um esforço excessivo para reunir todos os conhecimentos (dispersos, saliento) adquiridos e lidar com aquele sujeito integral que se encontra à sua frente necessitando de cuidado. Os alunos por vezes recorrem à especialização precoce, ou seja, decidem que área irão seguir ainda durante o curso, pois assim se sentem mais seguros para lidar com o sofrimento alheio (ou melhor, para lidarem com uma parte do sujeito que requer cuidados). Assim, passam a freqüentar precocemente serviços especializados, participam de atividades na área e seguem algum dos professores, despreocupando-se com as demais disciplinas. Em nossa sociedade, tal aspecto é valorizado: o aluno sente-se pressionado para dar resposta a questões do tipo "em que área você vai atuar?".

A formação acadêmica é, ademais, atualmente deficiente sob diversos ângulos: questiona-se a qualidade de ensino, bem como os métodos, os conceitos da relação médico-paciente e a compreensão do processo do adoecer são pouco ou sequer abordados, a dedicação excessiva à abordagem organicista e fragmentada do paciente, a especialização precoce do aluno, dentre outros aspectos.

\section{ALGUMAS REPERCUSSÕES DA IATROGENIA}

A repercussão psicossocial que uma situação iatrogênica terá depende, em grande parte, da qualidade da relação médico-paciente outrora estabelecida.

\section{O Médico Omite Sua Falha}

Especialmente nas relações pouco consistentes, cuja personalidade do médico é deveras narcísica, médico e paciente passam a ver no "erro" uma forma de fracasso, de modo que o paciente não vai tolerar isso, enfim, não concederá outra chance ou sequer aceitará um pedido formal de desculpas. A relação torna-se fragilizada ou mesmo cessa após o episódio. Geralmente, culmina com um processo jurídico no qual o paciente busca condená-lo por "erro médico".

Como exemplo, podemos citar o caso de uma paciente que, após ter sido submetida a uma cirurgia plástica reparadora nos seios, não foi totalmente esclarecida acerca dos cuidados que deveria manter no pós-operatório (evitar dirigir, movimentar-se, etc.). Ocorreram complicações com os pontos da cirurgia, de tal forma que surgiram cicatrizes que não mais desapareceram. Não satisfeita com os resultados, decidiu processar judicialmente o médico por erro médico. O processo arrastou-se por anos e não houve acordos. As perdas foram significativas para ambos, seja no âmbito do estresse, tempo desperdiçado com inúmeras audiências e até mesmo gastos financeiros relacionados às custas judiciais e advocatícias.

\section{O Médico Admite a Culpa}

Esse comportamento, ao contrário do anterior, predomina nas relações mais bem estruturadas. $O$ profissional lança mão de sua capacidade para ver, na sua humildade, a falha como uma busca do conhecimento. O paciente concede nova oportunidade ao médico. São comuns reuniões de conciliação entre ambas as partes para que procedimentos éticos não necessitem ser instaurados. O Conselho Regional de Medicina do Rio de Janeiro (Cremerj) criou uma espécie de instância em que médico e paciente em litígio são colocados frente a frente, de tal modo que os conflitos possam ser solucionados ali mesmo, sem que seja necessário dar início a um processo no Conselho ou mesmo Judicial.

Na psiquiatria, é comum pacientes processarem os médicos em virtude dos efeitos adversos dos medicamentos ou por terem de ser submetidos a sessões de eletroconvulsoterapia (ECT). Quando, na iminência de uma situação litigiosa, o psiquiatra tem uma oportunidade de explicitar com mais detalhes os porquês de tais procedimentos, o paciente compreende e concede nova oportunidade ao médico.

Não podemos olvidar que o médico possui significativa importância no processo. A despeito das grandes conquistas tecnológicas na área médica, reitero que a carência afetiva, a necessidade do toque e tantos outros aspectos relacionados ao contato humano são deveras valorizados pelo sujeito enfermo. 
Quantos não são os pacientes que, mesmo tendo efeitos adversos ou não obtendo sucesso com o uso de determinados fármacos, retornam aos seus médicos para comunicar-lhes isso? Uma boa relação médico-paciente garante segurança ao paciente.

Outros aspectos valorizados pelos pacientes e que contribuem para o estabelecimento de uma boa relação são: atendimento nos horários corretos, escuta ativa dos sofrimentos do pacientes, isto é, não se limitar aos aspectos somáticos, disponibilidade para atender o paciente em situações de emergência, paciência e tolerância.

\section{SOBRE A PREVENÇÃO DE IATROGENIAS: IMPORTÂNCIA DA EDUCAÇÃO MÉDICA}

Frente a essas situações, os aspectos relacionados à profilaxia das iatrogenias carecem ser comentados. Não só os médicos e os professores como também toda a sua equipe de saúde são responsáveis pela prevenção da iatrogenose. O tema necessita estar na pauta dos educadores, não somente dos cursos de pós-graduação ou "perdido" em algumas disciplinas, tal como a Psicologia Médica.

O futuro médico precisa ser mais bem informado, e a educação médica lhe fornecerá instrumentos para refinar sua sensibilidade social e desenvolver responsabilidade pessoal e profissional, objetivando, igualmente, enfatizar o aperfeiçoamento do médico, entendido aqui como melhor tecnificação e especialização. Isso favorece o aumento dos acertos e a diminuição de falhas iatrogênicas ${ }^{13}$.

Deve-se priorizar o resgate de um ensino médico pautado na busca da integralidade, em que o aluno possa lidar com diferentes profissionais de saúde, isolando-se menos e aprendendo com eles as suas formas de atuação, introjetando ademais o fato de que o trabalho em equipe é importante para o estabelecimento da integralidade. Esta é uma prática em afinidade com a boa medicina, posto que tende para o estabelecimento da escuta, valorizando os diferentes atores envolvidos no processo do cuidado (profissionais, estabelecimentos de ensino e pacientes) ${ }^{6}$.

Adotando uma posição de humildade, o futuro médico se equivoca menos, pois possui discernimento suficiente para questionar e trabalhar em equipe numa perspectiva integradora. $\mathrm{O}$ aluno deve compreender e respeitar o paciente como pessoa, identificando os reais fatores que o levaram a buscar os serviços médicos, conforme comentamos. Os professores de disciplinas como Psicologia Médica, Semiologia, Introdução à Prática Médica, Deontologia, Ética Médica e demais cadeiras clínicas e cirúrgicas devem abordar a questão, contribuindo para que o futuro médico possa, ainda em seus pri- meiros contatos com os pacientes, assimilar uma visão biopsicossocial destes, aprimorando-se dessa forma a relação estudante-paciente.

Perestrello $^{8}$ nos fala da necessidade de se adotar uma "visão transpessoal" do paciente e salienta que o profissional deve ser autêntico. Sustenta que é válida a prática da psicoterapia "implícita" durante a anamnese. É preciso que os profissionais aprendam a "ouvir" o paciente (mas não silenciá-lo, acrescento) e, nesse sentido, condena a anamnese dirigida.

Balint ${ }^{1}$, um dos maiores estudiosos da relação médicopaciente, reforça a importância do clínico geral (médico de família), sobretudo pela melhor qualidade do vínculo que é criado entre ambos (médico e sujeito enfermo) nesse tipo de prática médica. Este profissional está mais capacitado para tratar doentes e não apenas doenças.

Uma grande contribuição de Balint consiste nos "Grupos Balint" (também conhecidos como Grupos de Reflexão) ${ }^{9,14}$, espaço onde se pretende discutir a atitude médica, incluindo a participação de outros profissionais. Nesse ambiente, os aspectos psicológicos são valorizados. Praticados na formação universitária (permitindo a discussão de problemas inerentes à prática médica e ao ensino, como os conflitos psicológicos do aluno) e no cotidiano da equipe médica, esses grupos constituem importante fonte de enriquecimento dos valores humanísticos a serem resgatados. Os Grupos Balint, dessa forma, contribuem para tornar a relação médico-paciente mais saudável e consistente.

Finalmente, devem ser resgatados os demais atributos do médico, como intuição, empatia, humildade, capacidade de comunicação e resiliência. O professor possui destacada importância nesse processo. A escolha de determinada conduta terapêutica deve ser precedida de ampla discussão, numa perspectiva de horizontalidade, de modo que todos os benefícios e riscos em questão sejam considerados.

O debate deste tema é inesgotável. Acreditamos que a abordagem do assunto durante a formação médica contribui sobremaneira para a construção de sujeitos impregnados de uma identidade médica ética, saudável, e, portanto, menos iatropatogênica.

\section{REFERÊNCIAS}

1. Balint M. O médico, seu paciente e a doença. Rio de Janeiro: Atheneu; 1975.

2. Hoirisch A. Sinopse de psiquiatria: iatrogenias. Rio de Janeiro: Cultura Médica; 1993.

3. Tavares FM. As Contribuições da medicina psicossomática à formação médica. Rev Bras Educ Med. 2005; 29(1): 64-9. 
4. Padilha KG. Considerações sobre as ocorrências iatrogênicas na assistência à saúde: dificuldades inerentes ao estudo do tema. Rev Esc Enferm USP. 2001; 35(3): 28790.

5. Conselho Federal de Medicina. Código de Ética Médica. Resolução CFM no 1246/88. 14 ed. Rio de Janeiro: Navegantes Ed. Graf.; 2004.

6. Pinheiro R, Mattos R, orgs. Construção social da demanda: direito à saúde, trabalho em equipe, participação e espaços públicos. Rio de Janeiro: UERJ / ABRASCO; 2005.

7. Camargo Júnior KR. Biomedicina, saber \& ciência: uma abordagem crítica. São Paulo: Hucitec; 2003. Cáp.: Medicina, medicalização e produção simbólica: o trajeto histórico da medicina no ocidente.

8. Perestrello D. A medicina da pessoa. 3 ed. Rio de Janeiro: Atheneu; 1982.

9. Mello Filho J, org. Psicossomática hoje. Porto Alegre: Artes Médicas; 1992.

10. Capisano HF. Manifestações iatrogênicas: conflitos neuróticos do médico prejudicam o paciente. Ars Curandi. 1969; 2 (38).

11. Hoirisch A. O problema da identidade médica. Rio de Janeiro;1976. Doutorado [Tese] - Universidade Federal do Rio de Janeiro.

12. Cruz EMTN. Formando médicos da pessoa: o resgate das relações médico-paciente e professor-aluno. Rev Bras Educ Med. 1997; 21(2-3): 22-8.
13. Sorin M. Iatrogenia: problemática general. Buenos Aires: El Ateneo; 1975.

14. Mello Filho J. Concepção psicossomática: visão atual. 9 ed. São Paulo: Casa do Psicólogo; 2002.

\section{DEDICATÓRIA}

Dedico este ensaio ao professor José Luiz Furtado Curzio, grande educador que perpetuou seus ensinamentos sobre ética e princípios da prática médica entre os acadêmicos da Faculdade de Medicina de Valença (RJ); e ao professor Júlio de Mello Filho, pioneiro da Medicina Psicossomática brasileira, que resgatou o tema da iatrogenia, influenciando a formação de muitas gerações de médicos em nosso país, a quem agradeço pelo incentivo à pesquisa.

\section{Conflito de Interesse}

Declarou não haver.

\section{Endereço para correspondência}

Felipe de Medeiros Tavares Instituto de Medicina Social - Uerj

Rua São Francisco Xavier, 524 - 7º andar - Blocos D e E Maracanã

20559-900 - Rio de Janeiro - RJ

e-mail: felipemtavares@ims.uerj.br 